\title{
Gold, Mercury, and Silver Extraction by Chemical and Physical Separation Methods
}

\author{
Yaser Olyaei ${ }^{1}, \quad$ Sajjad Aghazadeh ${ }^{1}, \quad$ Mahdi Gharabaghi ${ }^{1}, \quad$ Hassan Mamghaderi ${ }^{1}$, \\ Jahanbakhsh Mansouri ${ }^{2}$
}

${ }^{1}$ University of Tehran, Tehran Iran; ${ }^{2}$ Pouya Zarkan Aghdareh Gold Plant, Takab Iran

\begin{abstract}
An agitation leaching method was used for gold extraction from Aghdareh mine samples. Mineralogical study showed that $58 \%$ of the gold particles were finer than $10 \mu \mathrm{m}$. In addition $3 \%$ of the grade in the sample was related to refractory gold. Experiments results showed that at the optimum condition gold recovery was $91.8 \%$ and silver, and mercury recoveries were $41.5 \%$, and $10.2 \%$, respectively. After performing cyanidation tests for 6 different fractions, it was concluded that the most unleached gold particles exist in the fraction size finer than $25 \mu \mathrm{m}$ and about $5 \%$ of gold particles in the fraction size larger than $25 \mu \mathrm{m}$ was not leached. Therefore, further comminution was applied which increased by about $3.57 \%$ of gold recovery and about $5 \%$ of silver recovery. Further comminution did not affect the recovery of mercury. In order to increase the mercury recovery and prevent from amalgamation of gold by mercury particles, Knelson gravity concentrator was used. The tailing of gravity method was examined using cyanidation tests by considering the optimum conditions. According to the final results, using the combination of these methods, gold recovery is increased to $93.3 \%$ and the recovery of mercury increased to $42.1 \%$ while the recovery of silver is $42.17 \%$, without noticeable change.
\end{abstract}

Key words: gold; silver; mercury; cyanidation; Knelson method

The recovery of gold can be accomplished via thorough leaching, gravity, flotation, bioleaching, high pressure oxidation, roasting or combination of these methods ${ }^{[1]}$. Each of these methods strongly depends on the chemical and physical properties of ore, and mineral occurrence state inside the ore ${ }^{[2]}$. Among these methods, cyanidation is the standard process for the recovery of gold and silver ${ }^{[3]}$. Cyanidation process due to its high efficiency and cost-effective matter has become the main leaching method for dissolution of gold ${ }^{[2]}$. The cyanidation reaction for gold and silver occurs according to Eqs.(1) and (2) ${ }^{[4]}$. Oxidation of gold is a prior process before dissolution of gold within alkaline medium. When gold is oxidized, gold cyano complex $\left[\mathrm{Au}(\mathrm{CN})_{2}\right]^{-}$is formed with the presence of cyanide ${ }^{[4,5]}$.

$$
\begin{aligned}
& 4 \mathrm{Au}+8 \mathrm{CN}^{-}+\mathrm{O}_{2}+2 \mathrm{H}_{2} \mathrm{O} \rightarrow 4\left[\mathrm{Au}(\mathrm{CN})_{2}\right]^{-}+4 \mathrm{OH}^{-} \\
& 4 \mathrm{Ag}+8 \mathrm{CN}^{-}+\mathrm{O}_{2}+2 \mathrm{H}_{2} \mathrm{O} \rightarrow 4\left[\mathrm{Ag}(\mathrm{CN})_{2}\right]^{-}+4 \mathrm{OH}^{-}
\end{aligned}
$$

The rate of gold dissolution is controlled by a number of parameters including cyanide and oxygen concentration, $\mathrm{pH} / \mathrm{Eh}$, particle size, solid-liquid interface, and temperature. Some of the above mentioned factors were investigated in the present work.

Mercury is one the most poisonous elements and its metallic form cannot be removed by chemical reactions or changed into unharmed forms. Mercury is associated with gold mining, and release of mercury into the environment remain a concern due to its health effects on humans and other organisms ${ }^{[6]}$. Mercury is of paramount importance in the chemistry of gold extraction. Due to its natural occurrence in the form of pure or cinnabar mineral accompanied with gold ores, it is considered an important impurity in the gold cyanidation process. Metallic mercury is capable of adsorbing metallic gold which reduces gold recovery in cyanidation ${ }^{[3]}$. Mercury strongly follows the chemistry and mechanism of gold cyanidation. According to the Eq.3, in the presence of

Received date: November 14,2015

Corresponding author: Mahdi Gharabaghi, School of Mining Engineering, College of Engineering, University of Tehran, Tehran Iran, Tel: 0098-21-82084556, Fax: 0098-21-88225384, E-mail: Gharabaghi@ut.ac.ir, m.gharabaghi@gmail.com 
cyanide it is converted to di- or tetra-cyano mercury complex which is highly water soluble. Mercury cyanide complexes compete closely with gold cyanide complexes for adsorption on the active carbons and even can be replaced with some gold cyanide ions on the active carbon ${ }^{[6]}$.

$$
4 \mathrm{Hg}^{2+}+6 \mathrm{CN}^{-}=\mathrm{Hg}(\mathrm{CN})_{2}+\mathrm{Hg}(\mathrm{CN})_{4}{ }^{2-}
$$

Centrifugal separators are not limited to gold but research is also being carried out in coal and hematite processing, as well for processing fine material ${ }^{[7]}$. Due to the Knelson concentrator capability in the recovery of finer and lager particles of gold, it has been broadly used in the gold extraction industry. Also, it is considered to be a key factor contributing to environmental issues. In gold plants, the gravity method is applied as a pretreatment process which reduces cost of operations ${ }^{[8]}$. Knelson Concentrators are almost always placed in the grinding circuits ${ }^{[9]}$.

The aims of the present study are to investigate the effective parameters in the cyanidation process, increasing the amount of mercury as a minor product by Knelson concentrator, and finally increasing the recovery of gold.

\section{Experiment}

The sample was taken from Aghdare mine which is located Takab, Iran. Ore samples with different grades were collected and then mixed with a specific ratio to produce a mean feed grade. This measured value was about $1.5 \mathrm{~g} / \mathrm{t}$ for Aghdare gold plant. Data show that $150 \mathrm{~g} / \mathrm{t}$ mercury exists in the form of cinnabar mineral inside the ore. Due to the presence of mercury, large portion of gold was lost. Sample size was reduced using cone and cylindrical crushers and ball mill. After comminution stage, $2 \mathrm{~kg}$ of homogeneous sample was prepared for leaching tests. Also, some amount of initial sample were taken to do further experiments with Knelson concentrator equipment.

Leaching tests were carried out using a mechanical agitator (Ika-RW20, Germany) within ambient pressure and temperature, inside a 3 liter container with $1 \mathrm{~kg}$ ground sample by Denver ball mill. During all experiments, $\mathrm{pH}$ of solution was adjusted with $\mathrm{pH}$ meter (744 Metrohm) to keep constant value of 10.5. Hydrated lime for increasing $\mathrm{pH}$ solution and sodium cyanide for dissolution of gold were selected which are currently used in Aghdare gold complex with industrial purity. At the end of each test, pulp was filtered and washed with distilled water. Solution and filter cake were analyzed by atomic adsorption spectrometry and yields were calculated. The most effective parameters on the cyanidation process were identified and optimized including feed size distribution, solid percent, cyanide concentration and time (changing one parameter and keeping constant other parameters at the same time). Finally, response values for gold, silver and mercury recoveries were carefully examined.

Gold and silver particle sizes were in submicroscopic level in Aghdare mine which prevented using of centrifugal method for recovering these metals. Taking into account this fact, Knelson concentrator method for the recovery of cinnabar mineral (density of $8.1 \mathrm{~g} / \mathrm{cm}^{3}$ ) was chosen. Gravity tests with Knelson concentrator equipment in the laboratory scale (KC-MD-2") were conducted with the bowl capacity of $1 \mathrm{~L}$ pulp feed rate of $1 \mathrm{~kg} / \mathrm{min}$, and $d_{80}=500 \mu \mathrm{m}$ for feed input (with regard to cinnabar mineral's degree of freedom).

Optical mineralogy (using the prepared polished and thin sections) and X-ray diffraction (XRD) studies were performed to define the main and the trace minerals and their interlocking.

\section{Results and Discussion}

\subsection{Sample characterization and deportment of gold}

\subsubsection{Sample mineralogy}

Main minerals are quartz, Muscovite, calcite, dolomite, and smectite as seen in Table 1. The result of optical mineralogy shows that Aghdare gold particles are mostly distributed as native gold (Fig.1). Amalgamation or electrum grains (gold, mercury, and silver alloys) rarely can be observed inside the ore (Fig.2). It is also found that gold particles are submicroscopic (Fig.3).

Chemical analysis was carried out using atomic absorption spectrometry (AAS). Based on the obtained results, the grades of gold, silver, and mercury in the sample are 1.5, 7.5, and 160 $\mathrm{g} / \mathrm{t}$, respectively.

Table 1 Constituents of Aghdare gold ore mine and its gold percentage

\begin{tabular}{|c|c|c|}
\hline Mineral & Formula & Amount $/ \mathrm{wt} \%$ \\
\hline Quartz & $\mathrm{SiO}_{2}$ & 25.7 \\
\hline Muscovite & $\mathrm{KAl}_{2}\left(\mathrm{Si}_{3} \mathrm{Al}\right) \mathrm{O}_{10}(\mathrm{OH}, \mathrm{F})_{2}$ & 10.4 \\
\hline Smectite & $\begin{array}{c}(\mathrm{Ca}, \mathrm{Na})_{7}(\mathrm{AlFeMg})_{4} \\
{\left[(\mathrm{SiAl})_{8} \mathrm{O}_{20}\right](\mathrm{OH})_{4} \cdot n \mathrm{H}_{2} \mathrm{O}}\end{array}$ & 8.6 \\
\hline Kaolinite & $\mathrm{Al}_{2} \mathrm{Si}_{2} \mathrm{O}_{5}(\mathrm{OH})_{4}$ & 5.6 \\
\hline Other silicates & - & 2.7 \\
\hline Calcite & $\mathrm{CaCO}_{3}$ & 21.0 \\
\hline Dolomite & $\mathrm{CaMg}\left(\mathrm{CO}_{3}\right)_{2}$ & 9.6 \\
\hline Barite & $\mathrm{BaSO}_{4}$ & 3.1 \\
\hline Jarosite & $\mathrm{KFe}_{3}\left(\mathrm{SO}_{4}\right)_{2}(\mathrm{OH})_{6}$ & 2.0 \\
\hline $\begin{array}{c}\text { Lead and } \\
\text { iron arsenates }\end{array}$ & - & 2.2 \\
\hline Goethite & $\mathrm{FeOOH}$ & 3.7 \\
\hline Hematite & $\mathrm{Fe}_{2} \mathrm{O}_{3}$ & 1.0 \\
\hline Magnetite & $\mathrm{Fe}_{3} \mathrm{O}_{4}$ & 0.3 \\
\hline Pyrolusite & $\mathrm{MnO}_{2}$ & 2.5 \\
\hline Anatase-Rutile & $\mathrm{TiO}_{2}$ & 0.2 \\
\hline Cinnabar & $\mathrm{HgS}$ & 0.02 \\
\hline Liberated gold & $\mathrm{Au}$ & (226) \\
\hline Electrum gold & $\mathrm{Au}<80 \%+\mathrm{Ag}>20 \%$ & $(8)$ \\
\hline Amalgamated gold & $\mathrm{Au}<80 \%, \mathrm{Ag}+\mathrm{Hg}>20 \%$ & (9) \\
\hline Carbonaceous material & $\mathrm{C}_{\text {org }}$ & 0.1 \\
\hline
\end{tabular}

Note: Values inside parenthesis are numbered particles in microscope. 


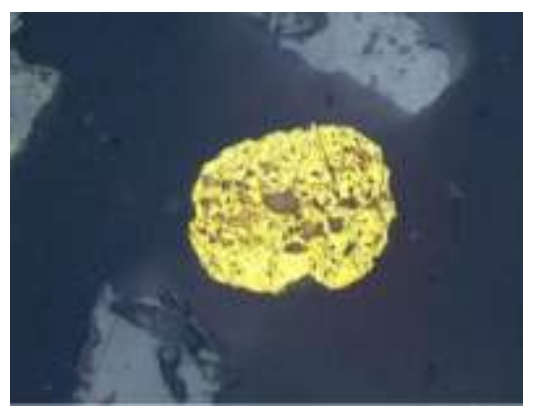

Fig.1 Original gold observation through optical microscopic

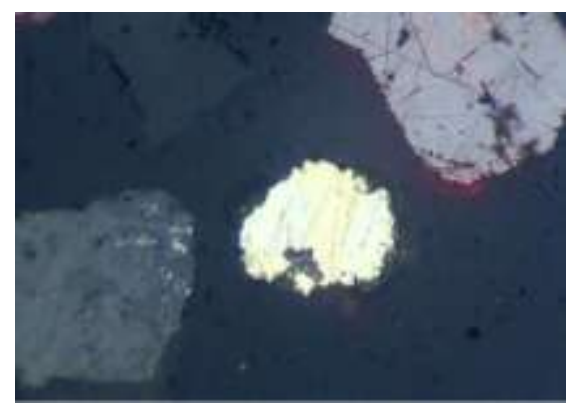

Fig.2 Au-Ag-Hg alloys; electrum [Au, Ag], $\mathrm{Au}-\mathrm{Ag}-\mathrm{Hg}$ amalgams

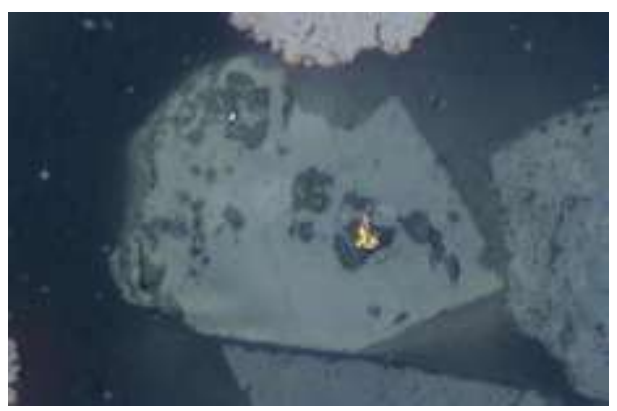

Fig.3 Enclosed gold in silicate, oxide, arsenate, and sulphide particles in the ore

\subsubsection{Deportment of gold in the sample}

Gold deportment and occurrence state were examined for the prepared sample in the ore. The results are given in Table 2.

Results show that gold particles finer than $10 \mu \mathrm{m}$ in Aghdare ore comprise $58 \%$ of all gold particles while particles with size greater than $10 \mu \mathrm{m}$ are inconsiderable. Due to the presence of $3 \%$ refractory gold in the ore suggested that using of the UFG (ultra-fine grinding) method for grinding of particles will liberate all gold particles. By applying the UFG method, maximum gold recovery will reach 97\% (gold particles show a connection with iron oxide minerals with a formula of $\mathrm{FeO}_{x}$ such as scorodite and jarosite). With regard to the presence of mercury in the ore and also due to the possibility of amalgamation of some liberated gold particles with this element, the recovery tends to decrease practically. Also about $8 \%$ of gold particles enclosed in arsenate and iron
Table 2 Deportment of gold particles in the sample

\begin{tabular}{|c|c|c|}
\hline $\begin{array}{l}\text { State of gold particles } \\
\text { in the feed sample }\end{array}$ & $\begin{array}{c}\text { Au amount/ } \\
\mu \mathrm{g} \cdot \mathrm{g}^{-1}\end{array}$ & $\begin{array}{l}\text { Au particle } \\
\text { amount } / \mathrm{wt} \%\end{array}$ \\
\hline Measured grade & 1.500 & 100 \\
\hline Liberated gold particles $(>50 \mu \mathrm{m})$ & 0.0001 & - \\
\hline Liberated gold particles $(10 \sim 50 \mu \mathrm{m})$ & 0.003 & 0.2 \\
\hline Liberated gold particles $(<10 \mu \mathrm{m})$ & 0.863 & 57.5 \\
\hline $\begin{array}{l}\text { Particles with at least one free surface } \\
\qquad(>50 \mu \mathrm{m})\end{array}$ & 0.127 & 8.5 \\
\hline $\begin{array}{l}\text { Particles with at least one free surface } \\
\qquad(10 \sim 50 \mu \mathrm{m})\end{array}$ & 0.336 & 22.7 \\
\hline $\begin{array}{l}\text { Gold trapped inside oxides and arsenates } \\
\qquad(>50 \mu \mathrm{m})\end{array}$ & 0.063 & 4.2 \\
\hline $\begin{array}{l}\text { Gold trapped inside oxides and arsenates } \\
\qquad(10 \sim 50 \mu \mathrm{m})\end{array}$ & 0.060 & 4.0 \\
\hline Unleachable particles inside sulfides & 0.048 & 3.2 \\
\hline
\end{tabular}

oxide minerals. For particles finer than $60 \mu \mathrm{m}, 89 \%$ of gold particles in the ore share at least one free surface and tend to be leachable.

2.1.3 Gold, silver, and mercury distribution in sample

Gold, silver, and mercury distribution of feed sample after grinding in each fraction are illustrated in Fig.4. The graph reveals that most gold particles in the ore (more than 70\%) are finer than $25 \mu \mathrm{m}$. Therefore, by UFG method which liberate all gold particles, gold recovery will reach its maximum value of $97 \%$. As shown in graph, silver and mercury distribution is very similar to gold. So we can use all of gold result deportment study for silver and mercury analysis. Also, because there is a considerable amount of gold in each fraction, we cannot recover most of gold particles in feed by gravity methods such as Knelson concentrator.

\subsection{Cyanidation study}

\subsubsection{Effect of particle size on recovery}

The effect of feed particle size on the recovery of gold, silver, and mercury was examined. Experiments were conducted using different values of particle sizes in the range of $25 \sim 75 \mu \mathrm{m}$. In these experiments, other parameters were kept constant including $1000 \mathrm{mg} / \mathrm{L}$ of cyanide concentration, $\mathrm{pH}$ of 10.5 , solid percent of $35 \%$, and leaching time of $24 \mathrm{~h}$. Results are

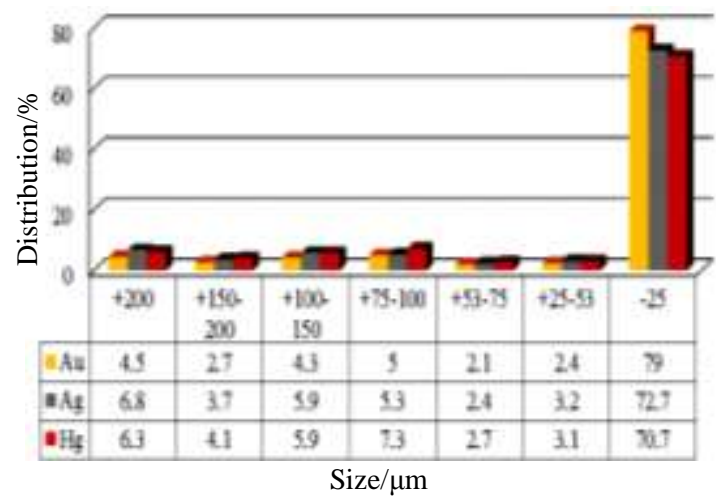

Fig.4 Gold, silver, and mercury distribution percent in each fraction after gridding samples 
illustrated in Fig.5 and Fig.6. Based on Fig.5, intensifying of comminution tends to liberate more gold particles which improves the recovery of gold. Optimum particle size is $37 \mu \mathrm{m}$ when gold recovery reaches $91.9 \%$. However, the obtained results shown in Fig.6 implies that intensifying of comminution will not affect the recovery of silver and mercury. Moreover, because of sulfide phase of mercury and silver leaching, their recovery is very lower than gold leaching recovery.

\subsubsection{Effect of leaching time on extraction}

In order to determine the optimum leaching time for cyanidation process, an experiment was conducted for $72 \mathrm{~h}$ and continually sampling from pulp was done for $2,4,8,24$, 48, and 72 h. Results shown in Fig.7 and Fig.8. According to Fig.7, gold dissolution rate is very high for $8 \mathrm{~h}$ leaching whereby the recovery of gold reaches $90.5 \%$. From $8 \mathrm{~h}$ to $24 \mathrm{~h}$ of leaching, gold recovery increases very slowly and then after $24 \mathrm{~h}$ it keeps almost a constant value. This may be because the dissolution of gold particles can be liberated or contacted with cyanides at the interface, and later by the dissolution of gold particles surrounded by silicate, oxide other minerals through diffusion. In the current experiment, the recovery of gold after $24 \mathrm{~h}$ of leaching is $92.1 \%$ which is regarded as optimum leaching time. Moreover, based on our observation in Fig.8, with increasing of leaching time, the recovery of silver and mercury tend to increase.

\subsubsection{Effect of solid percent on extraction}

In experiment we conducted tests for solid percent in the range of 35\% 50\%. Based on the results shown in Fig.9 and Fig.10, as solid percent value increases, the recovery of metals

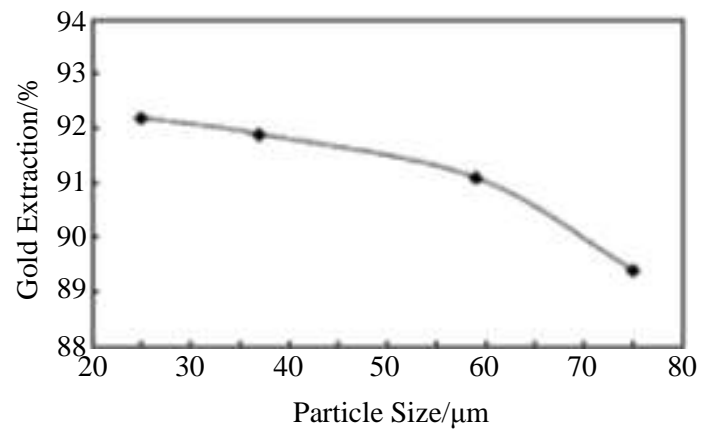

Fig.5 Effect of particle size on gold extraction

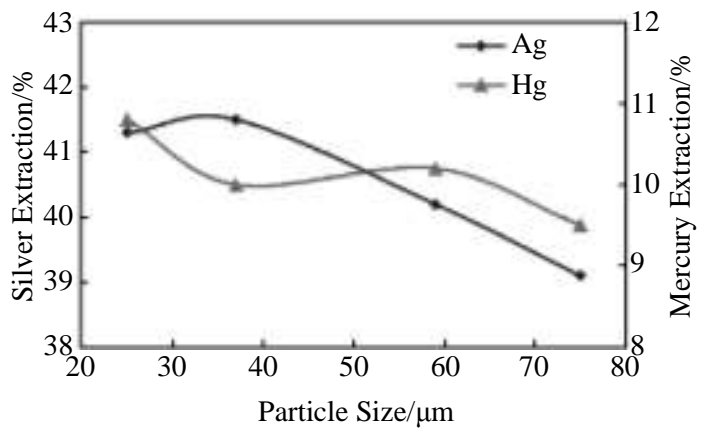

Fig.6 Effect of particle size on silver and mercury extraction

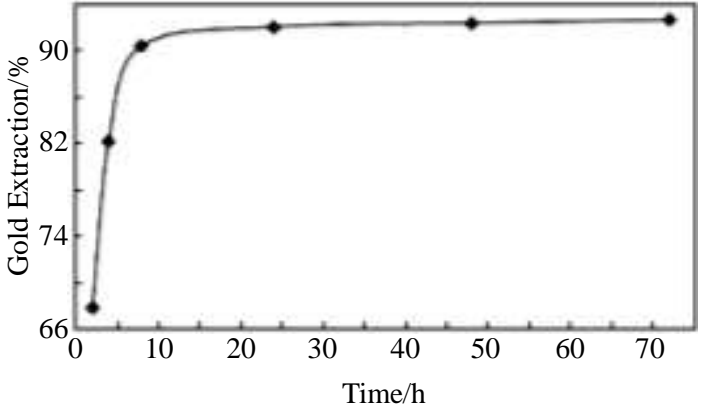

Fig.7 Effect of leaching time on gold extraction

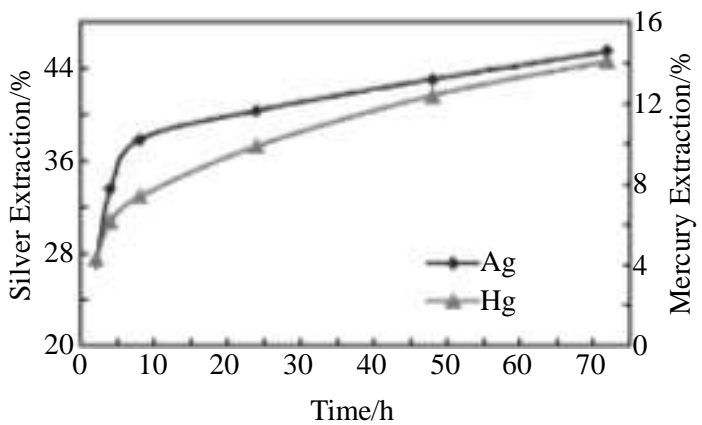

Fig.8 Effect of leaching time on silver and mercury extraction

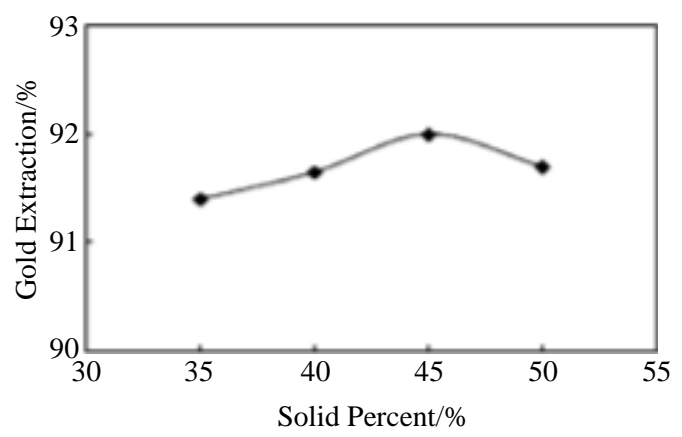

Fig.9 Effect of solid percent on gold extraction

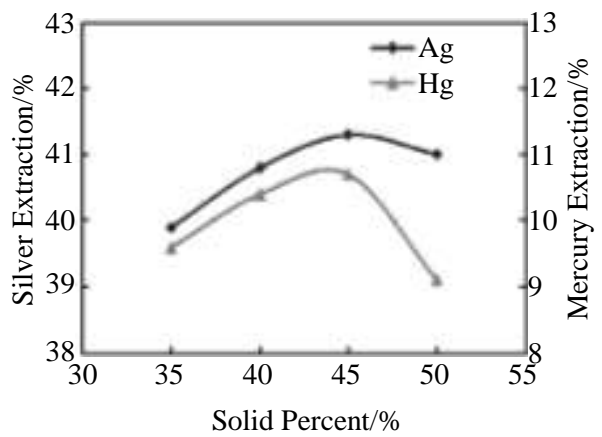

Fig.10 Effect of solid percent on silver and mercury extraction

increases; however, for solid percent greater than $45 \%$ the recovery of metals decreases. This is because of high pulp viscosity due to the presence of clay minerals and hydrate slime for adjusting $\mathrm{pH}$ of leach medium. 


\subsubsection{Effect of cyanide concentration on extraction}

In order to determine the optimum cyanide concentration, cyanide experiments with various concentrations were done. During the experiment other parameters including particle size, leaching time, and solid percent were kept constant at $37 \mu \mathrm{m}$, $24 \mathrm{~h}$, and 45\%, respectively. As shown in Fig.11 and Fig.12, increasing of cyanide concentration up to $1200 \mathrm{mg} / \mathrm{L}$ is in agreement with an increase in free cyanide ion in leach media. This increases the recoveries of gold, silver, and mercury to and they reach the values of $91.8 \%, 41.5 \%$, and $10.2 \%$, respectively. Cyanide concentration increase up to $1500 \mathrm{mg} / \mathrm{L}$ has no considerable effect on the recovery of gold and silver; however, this reduces the recovery of mercury to about $0.5 \%$. With regard to what we achieved from cyanide concentration experiment, the optimum cyanide concentration is considered to be $1200 \mathrm{mg} / \mathrm{L}$. Around this value, the concentration free cyanide ions inside pulp was measured with about $500 \mathrm{mg} / \mathrm{L}$.

\subsection{Leaching tests on each fraction}

Six distinct cyanidation tests were conducted for each fraction size. The recoveries of gold, silver, and mercury for each fraction size are given in Table 3. Experiment conditions are as follows: $\mathrm{pH}$ of 10.5 , leaching time of $24 \mathrm{~h}$, cyanide concentration of $500 \mathrm{mg} / \mathrm{L}$, and sample mass of $300 \mathrm{~g}$. According Table 3, the maximum recovery of gold, silver, and unleached mercury can be obtained for fraction size finer than $25 \mu \mathrm{m}$. Also, about $5 \%$ of all gold in feed are remained in fraction size greater than $25 \mu \mathrm{m}$. Consequently, by regrinding all particles to fraction size finer than $25 \mu \mathrm{m}$ and liberating valuable minerals we would be able to increase their recovery.

\subsection{Ultra-fine grinding (UFG) experiment}

In the present experiment, all large particles completely were ground to reach $100 \%$ fraction size finer than $25 \mu \mathrm{m}$. After blending, a homogenous sample was prepared. Then one specific test conducted by considering exactly previous experiment conditions. Results reveal that under these conditions the recoveries of gold, silver, and mercury become $92.55 \%, 38.7 \%$, and $13.5 \%$, respectively. It is obvious that further sample grinding improves the recovery of gold by about $5.25 \%$ and the recovery of silver by about $5 \%$; however, it does not have a noteworthy effect on the recovery of mercury.

2.5 Combination of Knelson concentrator and cyanidation method
The combination of Knelson concentrator and cyanidation method was carried out in order to improve the recovery of mercury as cinnabar mineral and also increase the recovery of gold during leaching process. In this case, Knelson concentrator tests were applied to determine the optimum pressure of equipment so as to obtain the maximum recovery of mercury in the concentrate and minimum value of grade in the tailing section. Then, Knelson's tailing went through cyanidation operation. According to the results of Knelson's experiments as shown in Fig.13, cinnabar concentrate with the grade value of $39.86 \%$ and recovery value of $37 \%$ can be achieved at 11 psi $\left(75.85 \times 10^{3} \mathrm{~Pa}\right)$ of water back pressure. Moreover, mercury grade in Knelson's tailing is decreased to $53 \mu \mathrm{g} / \mathrm{g}$. Cyanidation experiments on Knelson's tailing under optimum conditions show that the recovery of gold increases by $1.5 \%$; however, the recovery of silver does not change considerably. Based on the final results, total recoveries of gold, silver and mercury

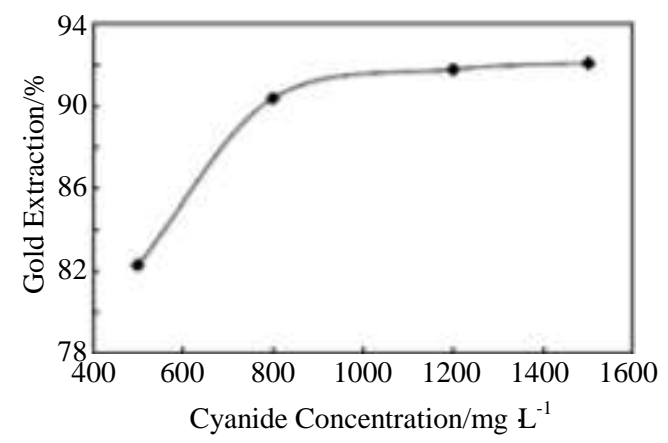

Fig.11 Effect of cyanide concentration on gold extraction

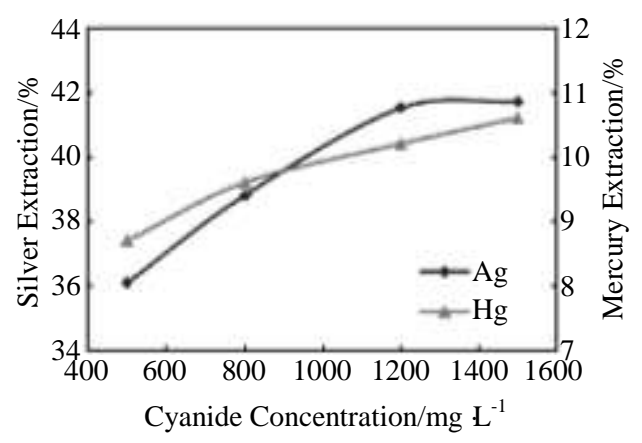

Fig.12 Effect of cyanide concentration on silver and mercury extraction

Table 3 Measured recovery and unleached of gold, silver, and mercury for each fraction size

\begin{tabular}{|c|c|c|c|c|c|c|}
\hline Fraction size/ $\mu \mathrm{m}$ & Au recovery $/ \%$ & Au unleached $/ \%$ & Ag recovery $/ \%$ & Ag unleached $/ \%$ & $\mathrm{Hg}$ recovery $/ \%$ & $\mathrm{Hg}$ unleached $/ \%$ \\
\hline 200 & 3.2 & 1.24 & 1.6 & 5.15 & 0.7 & 5.5 \\
\hline 150 200 & 2 & 0.74 & 0.3 & 3.34 & 0.7 & 3.34 \\
\hline $100 \sim 150$ & 3.3 & 1.02 & 1.4 & 4.5 & 0.8 & 5.11 \\
\hline $75 \sim 100$ & 3.6 & 1.36 & 0.7 & 4.64 & 1.1 & 6.22 \\
\hline $53 \sim 75$ & 1.7 & 0.46 & 0.1 & 2.3 & 0.2 & 2.45 \\
\hline $25 \sim 53$ & 1.7 & 0.68 & 0.5 & 2.71 & 0.2 & 2.88 \\
\hline$<25$ & 71.8 & 7.2 & 29.1 & 43.6 & 10.9 & 59.7 \\
\hline Sum & 87.3 & 12.7 & 33.7 & 66.3 & 14.6 & 85.2 \\
\hline
\end{tabular}




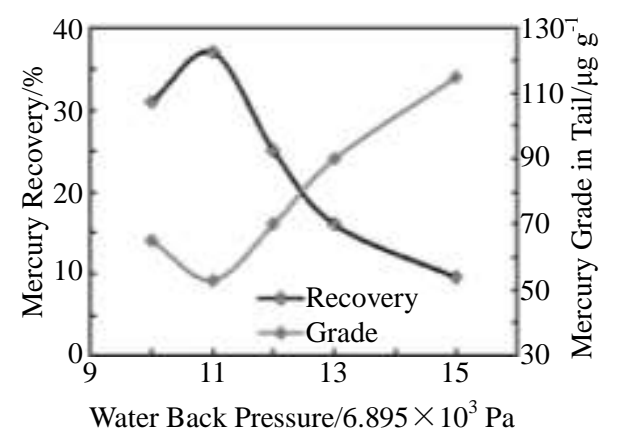

Fig.13 Knelson experiment results for different water pressures

are $93.3 \%, 42.17 \%$, and $42.16 \%$ (37\% as cinnabar mineral), respectively, when the combination of two methods applied.

\section{Conclusions}

1) Gold particles in Aghdare ore are in submicroscopic level. Liberated gold particles finer than $10 \mu \mathrm{m}$ comprise $58 \%$ of all gold particles and gold particles greater than $10 \mu \mathrm{m}$ have inconsiderable portion in the ore. Also, refractory gold accounts for $3 \%$ of the grade. Complete liberation of gold particles in the sample occurred in fraction size finer than 10 $\mu \mathrm{m}$. A substantial portion of gold particles in the ore (more than $70 \%$ ) exists in fraction size finer than $25 \mu \mathrm{m}$.

2) Optimum conditions for cyanidation experiment are as follows: feed $d_{80}=37 \mu \mathrm{m}$, cyanidation time of $24 \mathrm{~h}$, solid percent of $45 \%$, and cyanide concentration of $1200 \mathrm{mg} / \mathrm{L}$ in constant $\mathrm{pH}$ of 10.5 . Under these optimum conditions, the recovery of gold, silver, and mercury are $91.8 \%, 41.5 \%$, and $10.2 \%$, respectively.

3) The maximum unleached gold, silver, and mercury tend to be in fraction size finer than $25 \mu \mathrm{m}$. Also, about $5 \%$ of all gold particles in the feed are remained in the fraction size greater than $25 \mu \mathrm{m}$. Therefore, by further comminution (finer than $25 \mu \mathrm{m}$ ) and liberation of valuable particles, the recovery of gold can increase by $3.57 \%$ and the recovery of silver by $5 \%$; however, the recovery of mercury can not be affected.

4) The combination of two Knelson concentrator and cyanidation methods can obtain the total recovery of gold $93.3 \%$, silver $42.17 \%$, and mercury $42.16 \%$ (37\% as cinnabar mineral). For water pressure of $75.85 \times 10^{3} \mathrm{~Pa}$ and feed distribution size of $500 \mu \mathrm{m}$, the cinnabar concentrate with mercury grade of $39.89 \%$ and mercury recovery of $37 \%$ can be obtained.

\section{References}

1 Adams M. Developments in Mineral Processing[M]. MO: Elsevier, 2005, 15: 994

2 Yannopoulos J C. Van Nostrand Reinhold[M]. New York: Elsevier, 1991

3 Marsden J, House I. Cyanidation is the Standard Process for the Recovery of Gold and Silver[M]. Society for Mining and Metallurgy, 2006

4 Kondos P, Deschênes G, Morrison R. Hydrometallurgy[J], 1995, 39(1): 235

5 Olyaei Y, Noparast M et al. 14th International Mineral Processing Symposium[C]. Kuşadasi, Turkey: IMPS, 2014: 562

6 Jones G, Miller G. Mercury and Modern Gold Mining in Nevada[R]. Nevada: University of Nevada, 2005

7 Greenwood M, Langlois R, Waters K. Minerals Engineering [J], 2013. 45: 44

8 Ounpuu M. 24th Annual Meeting of the Canadian Mineral Processors[C]. Ottawa: Ontario, Canadá, 1992

9 Laplante A, Woodcock F, Noaparast M. Minerals and Metallurgical Processing[J], 1995, 12(2): 74

\title{
化学和物理分离法萃取金、永、银
}

\author{
Yaser Olyaei ${ }^{1}$, Sajjad Aghazadeh ${ }^{1}$, Mahdi Gharabaghi ${ }^{1}$, Hassan Mamghaderi ${ }^{1}$, Jahanbakhsh Mansouri ${ }^{2}$ \\ (1. 德黑兰大学, 德黑兰 伊朗) \\ (2. Pouya Zarkan Aghdareh 金厂，Takab 伊朗)
}

\begin{abstract}
摘 要: 采用搅拌过滤法对 Aghdareh 金矿样品进行金的萃提。矿物学研究表明, 样品中 $58 \%$ 的金颗粒小于 $10 \mu \mathrm{m}$, 该等级的 $3 \%$ 属于难 熔金。实验结果表明，在最优条件下，金回收率可达 $91.8 \%$, 银和录分别为 $41.5 \%$ 和 $10.2 \%$ 。以氰化法测试的 6 种分次尺寸样品的结果表 明, 未萃取的金粒子大多小于 $25 \mu \mathrm{m}$, 还有大约 $5 \%$ 的金颗粒大于 $25 \mu \mathrm{m}$ 。因此, 对样品要进一步粉碎, 这样可使金和银回收率分别提高 约 3.57\% 和约 5\%, 进一步粉碎样品并不影响录的回收率。采用 Knelson 重力选矿法可提高录回收率并防止金和录的混合, 利用氧化法检 测重力法的尾料。这些方法的结合应用, 最终使金回收率达到 $93.3 \%$, 永回收率增加到 $42.16 \%$, 而银回收率没有明显的变化, 为 $42.17 \%$ 。 关键词: 金; 银; 录; 氧化法; Knelson 方法
\end{abstract}

作者简介: Yaser Olyaei, 德黑兰大学工程学院矿业工程系, 德黑兰 伊朗, 电话: 0098-21-82084556, Fax: 0098-21-88225384, E-mail: 